RESEARCH NOTE

\title{
China Town as a multilingual workplace
}

\author{
Miché Thompson \\ Department of General Linguistics, Stellenbosch University \\ E-mail: thompson.michechanelle@gmail.com
}

\begin{abstract}
Since the emergence of China within the BRIC ${ }^{1}$ group in 2001 (BRICS as from 2010), people of Chinese origin have gradually secured a market share in Africa that is successful at both formal and informal levels. A fitting example present at the informal level is the establishment of China Town stores and Chinese markets. These Chinese markets are characterised as a network of small, family-owned businesses which sell goods imported from China at competitive prices. This business model has become part of most towns and cities in Africa, with Chinese-owned stores featuring in lower- and middle-class areas. Overwhelmingly, the stores are managed by Chinese patrons who employ shop assistants of African migrant origin. Both groups have integrated themselves into specialised occupations, with the Chinese traders opening these (in)formal stores and the African traders working closely with them as shop assistants. The shopkeepers and their assistants speak different languages, but living and working in a multilingual South Africa, they communicate in English which is the common lingua franca. This research report presents an overview of an ongoing doctoral study which focuses on the Chinese markets in South Africa, with a specific interest in the nature of interaction between the Chinese shopkeepers and their African shop assistants. It seeks to describe and explain how language-in-interaction is performed or socially produced, where participants do not have a common first language, and English is the lingua franca. The data comprises audio recordings of the interaction between shopkeeper and assistants throughout the workday, as well as field notes from observations of the research site. The ongoing study wishes to describe what happens linguistically when these different groups of migrants find themselves in new social and linguistic environments to which they acclimatise in interesting ways.
\end{abstract}

Keywords: China Town, shopkeepers, shop assistants, multilingualism, Linguistic Ethnography, Conversation Analysis, Critical Discourse Analysis

\footnotetext{
${ }^{1}$ BRIC: abbreviation for rapidly developing economies in Brazil, Russia, India and China, coined in 2001; in 2010 South Africa joined, so that then the group became "BRICS".
} 


\section{Overview and research questions}

With the introduction of representative government post-1994, South Africa has seen a significant influx of migration into and out of the country. Driven by factors such as warfare, poverty, overpopulation, and unemployment, South Africa has become a destination of opportunity for migrants from all over the African continent as well as some parts of Asia. Jobs available for these migrants are often in the unskilled sectors such as transport, agriculture, hospitality, and, as is relevant to this project, various forms of trade. One community that has proven success in establishing trade businesses is the Chinese community. The established pattern is that these businesses employ African migrants or local unemployed people as shop assistants.

Considering their various countries of origin, the shopkeepers and assistants speak different first languages (L1s) and have diverse linguistic repertoires. The store owners and assistants have mutually unintelligible first languages, but living and working in a multilingual South Africa where English is the lingua franca, they communicate in English which is the common language. This brings into focus the issue of communication between shopkeeper and assistant in the workplace. The ongoing research aims to describe the creative ways in which store owners and assistants, both with different first languages, communicate in the workplace where English is used as lingua franca in a multilingual space. Thereupon, the overall objective is to explore multilingualism and the creative use of the participants' linguistic repertoires to negotiate meaning in interaction. The study seeks to describe and explain how language-in-interaction is performed or socially produced where participants do not have a common first language and English is the lingua franca.

The research seeks to answer one overarching question, namely: what are the characterising features of communicative events where English is used as lingua franca in the workplace between Mandarin L1 shopkeepers and shop assistants with an African language as L1? This is divided into the following sub-questions:

1. What are the language biographies of the participants? Which languages make up the linguistic repertoire of shopkeepers and shop assistants in China Town stores?

2. What are the communicative strategies typically used between the various participants? Which of these appear to be typical of such language contact situations, and which appear to be new, i.e. not recorded in previous studies of workplace communication between speakers of mutually unintelligible languages while in a foreign country.

3. What kinds of misunderstandings occur in the communication, and how are they recognised and resolved?

4. How can the conversations between shop owners and shop assistants in the shop as workplace be categorised in generic terms, e.g. discussion of stock, giving and receiving instructions, conversation between owner and assistant on client relations, and the like?

\section{Multilingualism in the workplace}

The framework which the research addresses is that of multilingualism, specifically focusing on multilingualism in the workplace. The term "multilingualism" is widely conceptualised as 
the knowledge of and ability to use several languages. It describes languages, dialects, and language varieties within an individual's linguistic repertoire, with a focus on how individuals use these fluidly and creatively in interaction. It is both an individual, social, and cultural way of using language and language varieties in various domains of interaction. As expressed by Bailey (2007: 342), "multilingual individuals have an expanded set of linguistic resources for the omnipresent task of positioning self and other". Multilingualism is a phenomenon that pervades different levels of life, and, according to Pietikäinen et al. (2008), entire societies can be multilingual but so can smaller groups and individuals. Thus, institutional, societal, family, and individual multilingualism may be observed.

Multilingualism has been widely studied in institutional settings, with a focus on how people communicate when there is a need for a common language. The institutions that form part of the discourse on multilingualism predominantly include the likes of classroom and higher education, government, health sectors and, more relevant to this study, the workplace. Although discourse on multilingualism in various institutions provides a valuable framework for conceptualising this research, the significance of this project is that it looks at a form of multilingualism that has not been investigated in the workplace as an informal (not characterised as institutional) space.

Interest in workplace communication is not a new phenomenon, especially since multilingualism has become a norm in today's globalised economy, as expressed in Roberts (2007). This has led to widespread scholarly interest in linguistic practices in the workplace as communicative context. In the Australian context, Clyne (1994) conducted an intercultural study on spontaneous workplace interaction. His study focused on lingua franca communication between workers with various linguistic backgrounds, and how communication takes place within official meetings and interactions in the Australian workplace. Similarly, Roberts (2007) focused on migrant workers in stores as well as service and health industries, with a view into educational and training programmes in these workplaces. In the commerce sector, Li (2007) sought to identify the ways that people in multilingual business environments communicate where they have different language backgrounds and varying multilingual proficiency. His research shows that in the commercial environment, "a high level of proficiency in the world's major languages of wider communication is one of the most frequently cited requirements for the multilingual workplace" (Li 2007: 429). In the South African context, Hill and Van Zyl (2002) investigated the linguistic context of the engineering field. Their findings show that although employees are multicultural and multilingual, and use their first languages in the workplace, English is still the language used when communicating with superiors. English was also shown to be used across a range of interactions including meetings, documentation, and teamwork (Hill and Van Zyl 2002: 27).

Although the research above presents us with a useful theoretical and conceptual lens for understanding multilingualism in the workplace, the context for this study is an informal workplace where there is no institutionally structured way of conducting business as with the studies cited above. It is a workplace where the employees do not have a formal recruitment process, have irregular income and low wage, and have no employee benefits or access to credit. The most significant requirement posed by the employer is that the employee is able to speak sufficient English to assist customers in the stores. In this context, where the basic requirement is "just enough English to get by", the communicative practices are markedly different from that of more sophisticated institutionalised workplaces as referenced by Li (2007) and Roberts (2007). 
More relevant to the context of this research is Han's (2013) study which explored multilingualism in an African marketplace in Guangzhou, China. She specifically investigated how Africans and Chinese in a Guangzhou marketplace as an informal workplace expanded their multilingual repertoires through multilingual interactions. What is particularly of interest is that she found her participants to have developed a language variety cleverly coined "Chinglish", which she describes as a lingua franca that emerged as a result of the language contact between Chinese and Africans working in the markets (Han 2013). This kind of language contact has led to a particular way of conceptualising multilingualism in such an informal space, a concept that Han refers to as "grassroots multilingualism". The concept of 'grassroots multilingualism' is used throughout this study, as the context in focus deals with a particular kind of language contact phenomenon that takes place on a grassroots level.

\section{Research design and data analysis}

As stated above, the research is conducted amongst migrant employers and employees working in three different stores. The participant population comprises three shopkeepers of Chinese migrant origin, five shop assistants of African migrant origin, and two shop assistants from South Africa. The data here is the audio recordings of their spontaneous interaction throughout the business day, for a period of five weeks, with the research focusing on how they use English as the language of wider communication, and which specific conversational strategies develop as generic means of workplace interaction.

In order to analyse and describe the communicative practices that occur in a multilingual workplace, this study requires transcriptions of recorded interactions between the participants in each store throughout the workday. The recorded data is comprised of spontaneous unscripted conversation between employers and employees that were captured using mobile recording devices and lapel microphones. The recordings, constituting the primary data for this study, were later transcribed, and the transcriptions integrated with the field notes made during observation were then analysed.

For the phenomenon being researched, a linguistic ethnography addresses the complexities within the context of the communicative events to be investigated. The research adopts a linguistic ethnography for the collection and analysis of data. For Rampton (2007), people, situated encounters and institutions are interconnected, and linguistic ethnography provides an approach that addresses this link, which is particularly useful in the context of the informal workplace. Drawing on pragmatics and linguistic ethnography, the project adopts an interactional sociolinguistic approach, which links a micro-level analysis of interactional structures (in this instance Conversation Analysis) to macro issues within the wider social debate. An interactional sociolinguistic approach methodologically includes ethnographic observation to inform the recorded data when reflecting on the spoken interaction. Similarly, Roberts (2007: 415) points out that a linguistic ethnography "allies the focus on recorded and analysed discourse with a study of the communicative ecology of the workplace and the subjectivities that sustain it”. Rampton (2007: 591) states that linguistic ethnography:

meshes well with discourse analysis, which is often centrally involved in stepping back from the easy flow of communicative practice, interrogating its components, underpinnings and effects. For example, in spite of some striking differences [...] both Critical Discourse Analysis and Conversation Analysis provide ways of 
stepping back from the taken-for-granted in order to uncover the ideological (CDA) or interactional (CA) processes that constitute common-sense and everyday practice.

The study hence takes its Conversation Analysis and Discourse Analysis approach from the interdisciplinary work of linguistic ethnography, which integrates the study of language and communication with ethnography as a resource. These frameworks have proven to be highly suitable for engaging with the kind of phenomena observed and analysed in a study of spontaneous and unscripted workplace conversation as it occurs in real time (see Schegloff et al. 2002).

Although Discourse Analysis and Conversation Analysis developed as two ideologically different approaches, this study deals with everyday human interaction, so certain aspects of interaction could not be overlooked in the analysis. Although a description of communicative practices in a language contact situation was done by looking at the structure and organisation of turns (Conversation Analysis), the issue of larger communicative strategies signifying power and relationship dynamics cannot be ignored in this context (Discourse Analysis). Discourse Analysis considers spoken language events, considers speech-act types and speechaction sequences, and considers on a textual level what the formal and contextual features of a discourse type are.

To analyse the data from a Discourse Analysis perspective, I used Gee's (2011) conceptualisation of language as a way of saying, being and doing. This means that I analysed the conversation with specific questions in mind, namely: what is happening in this interaction? What are participants trying to do with their talk? What identities do they take on in their talk? How do they position themselves through talk? By asking these questions, I was able to recognise and explicate the participants' positions in the data.

As the interest of this research is the negotiation of meaning where there is varying proficiency in English among the participants, Conversation Analysis was used to identify the practices and patterns that enable interlocutors in an interaction to be able to interact in a co-constructive way. For this reason, Conversation Analysis is the principle analytical tool, and, when used within an interactional sociolinguistic approach, it not only accounts for the spoken interaction between two migrant groups, but also the contribution to the communicative encounters of the context within which their interaction takes place. It allows for description and explanation of what happens linguistically and, together with the interactional sociolinguistic approach, also allows for a description of what happens socially in the organisation of workplace communication. Conversation Analysis discloses covert and often unconscious interactional rules within specific contexts, and for this reason has been selected for an investigation of interaction in a situation of language contact in the workplace.

\section{Conclusion}

This report has provided an overview of an ongoing study that investigates communicative practices of two migrant groups in South Africa in their workplace interactions. The study forms part of a larger research interest in the languages of migrant communities, and how these feature in speakers' integration into the receiving community. The study not only describes and explains patterns of multilingual communication, it also reflects on a particular kind of language contact situation, and contributes to new knowledge of how groups with vastly different first languages and communicative cultures manage contact in the workplace. 


\section{References}

Bailey, B. 2007. Multilingual forms of talk and identity work. In P. Auer and L. Wei (eds.) Handbook of multilingualism and multilingual communication. Berlin: Mouton de Gruyter. pp. 341-370. https://doi.org/10.1515/9783110198553.3.341

Clyne, M. 1994. Inter-cultural communication at work: Cultural values in discourse. Cambridge, UK: Cambridge University Press. https://doi.org/10.1017/cbo9780511620799.003

Gee, J.P. 2011. An introduction to discourse analysis. $3^{\text {rd }}$ Edition. London: Routledge.

Han, H. 2013. Individual grassroots multilingualism in Africa Town in Guangzhou: The role of states in globalization. International Multilingual Research Journal 7: 83-97. https://doi.org/10.1080/19313152.2013.746803

Hill, P. and S. van Zyl. 2002. English and multilingualism in the South African engineering workplace. World Englishes 21: 23-35. https://doi.org/10.1111/1467-971x.00229

Li, D.C.S. 2007. Multilingualism and commerce. In P. Auer and L. Wei (eds.) Handbook of multilingualism and multilingual communication. Berlin: Mouton de Gruyter. pp. 423-443. https://doi.org/10.1515/9783110198553.3.423

Pietikäinen, S., R. Alanen, H. Dufva, P. Kalaja, S. Leppänen and A. Pitkänen-Huhta. 2008. Languaging in Ultima Thule: Multilingualism in the life of a Sami boy. International Journal of Multilingualism 5(2): 79-99. https://doi.org/10.2167/ijmb083.0

Rampton, B. 2007. Neo-Hymesian linguistic ethnography in the United Kingdom. Journal of Sociolinguistics 11(5): 584-607. https://doi.org/10.1111/j.1467-9841.2007.00341.x

Roberts, C. 2007. Multilingualism in the workplace. In P. Auer and L. Wei (eds.) Handbook of multilingualism and multilingual communication. Berlin: Mouton de Gruyter. pp. 405-422. https://doi.org/10.1515/9783110198553.3.405

Schegloff, E.A., I. Koshik, S. Jacoby and D. Olsher. 2002. Conversation analysis and applied linguistics. Annual Review of Applied Linguistics 22: 3-31.

https://doi.org/10.1017/s0267190502000016 